\title{
Non dimensional analysis and characterisation of driving forces for a single sided slot louver ventilation system
}

\author{
Paul D O’Sullivan ${ }^{1,2}$, Maria Kolokotroni ${ }^{2}$ \\ ${ }^{1}$ Cork Institute of Technology, Rossa Avenue, Bishopstown, Cork, Ireland \\ ${ }^{2}$ Brunel University, Uxbridge UB8 3PH, United Kingdom
}

\begin{abstract}
Adopting natural ventilation as a low impact retrofit strategy for space cooling is attractive due to the cooling potential of untreated outdoor air for large periods of the extended cooling season, particularly in northern climates. Furthermore, it is important to characterise the performance of natural ventilation components in successfully transferring the cooling potential of outdoor air to the occupied zone. This paper presents an analysis of the results from 25 individual ventilation rate tests of a single sided slot louver ventilation system installed in a low energy retrofit application and 13 tests from a pre-retrofit window opening, taken as a control space. Parameters permitting characterisation of different permutations for combined momentum and buoyancy driving forces during each test were also recorded allowing an investigation of the existence of any underlying patterns as well as the relative effect of the different opening configurations. Analysis shows that different patterns emerge for the dominant driving forces depending on opening configuration in the slot louver system. Owing to the primary airflow exchange mechanisms normally present, the transient evolution of the normalised tracer gas concentration during tests is analysed using the concentration fluctuation amplitude. The slot louver ventilation system has led to steadier ventilation rates. Opening height and geometry is shown to have a significant effect on the net contribution from momentum driving forces and the fluctuation amplitude of the ventilation rate and this effect is wind direction dependant. Ventilation rates are shown to correlate well with fluctuation amplitude. The nature of the ventilation rate during tests for different wind directions is shown to vary depending on wind patterns at the building envelope.
\end{abstract}

Keywords: mean and fluctuating ventilation, dominant forces, warren plot, buoyancy asymptote

\section{INTRODUCTION}

While experimental data exists for single sided ventilation rates, (Dascalaki et al 1996) (Dascalaki et al. 1995) (de Gids and Pfaff. 1982) (Caciolo et al 2011), information is not exhaustive for openings other than common window types. Single sided ventilation techniques are generally reserved for single cell (Irving et al 2005), isolated spaces and when considering older office buildings that need retrofitting, the floor plan can often be designed in this manner and not intended as open plan spaces. Developing ventilation components that can be applied externally in a retrofit program, provide sufficient weather protection and are effective at ensuring good ventilation rates by responding to contributing airflow mechanisms is central to ensuring successful implementation of climate change adaptation strategies. This paper presents an analysis of the mechanisms contributing to time average single sided ventilation rates from test results for a slot louvre ventilation component operated as part of a single sided ventilation strategy. It considers two key aspects of the ventilation rate; the combined effect of momentum and buoyancy forces on mean ventilation rates and analysis of the nature of the ventilation rate during tracer decay tests using a fluctuation parameter, $\sigma_{c n}$. The objective is to investigate the conditions contributing to mean ventilation rates for a slot louvre system used in single sided ventilation. Data presented was recorded in a full scale test room for different opening configurations. 


\begin{tabular}{|c|c|c|c|}
\hline \multicolumn{4}{|c|}{ Nomenclature } \\
\hline \multicolumn{2}{|c|}{ Symbols } & \multicolumn{2}{|c|}{ Subscripts } \\
\hline$A r$ & Archimedes Number & $i$ & inside \\
\hline$F$ & Flow Number & $o$ & outside \\
\hline$C_{d}$ & discharge coefficient & ie & internal to external \\
\hline$R e$ & Reynolds Number & $A C H$ & Air change rate \\
\hline$T$ & temperature $(\mathrm{K})$ & $t$ & Tracer, total \\
\hline$H$ & height, (m) & th & Thermal, stack effect \\
\hline$g$ & Acceleration due to gravity, $\left(\mathrm{m} / \mathrm{s}^{2}\right)$ & ope & opening \\
\hline$v$ & Velocity (wind), (m/s) & $e$ & effective \\
\hline$Q$ & Mean ventilation rate, $\left(m^{3} s^{-1}\right)$ & $w$ & wind, test space envelope wall \\
\hline$A$ & opening area $\left(\mathrm{m}^{2}\right)$ & $N$ & Normalised concentration \\
\hline$\beta$ & Power law exponent & int & Zone interior \\
\hline $\mathrm{L}$ & Characteristic length (m) & $\mathrm{h}$ & hydraulic \\
\hline$\rho$ & Density $\left(\mathrm{kg} / \mathrm{m}^{3}\right)$ & $c n$ & concentration (relating to fluctuations) \\
\hline C & tracer gas concentration (ppm) & $c$ & Particular combination \\
\hline$t$ & time, $(\mathrm{h})$ & $i$ & Parameter \\
\hline$P$ & Total pressure $\left(\mathrm{kg} / \mathrm{ms}^{2}\right)$ & $j$ & Parameter \\
\hline$\sigma$ & standard error of estimate of predictions & $b$ & Baseline buoyancy asymptote \\
\hline $\mathrm{K}$ & Variable, $1 / 3 C_{d}$ & $\mathrm{R}$ & Reference Flow Number \\
\hline$\xi$ & Flow resistance & & \\
\hline$\alpha$ & Flow coefficient & \multicolumn{2}{|c|}{ Abbreviations } \\
\hline $\mathrm{b}$ & Linear flow coefficient & CS & Control space \\
\hline \multirow[t]{4}{*}{$p$} & pressure $\left(\mathrm{kg} / \mathrm{ms}^{2}\right)$ & $\mathrm{RS}$ & Retrofit space \\
\hline & & $\mathrm{P}$ & Parallel direction \\
\hline & & $\mathrm{L}$ & Leeward direction \\
\hline & & $\mathrm{W}$ & Windward direction \\
\hline
\end{tabular}

A literature review has revealed little reported work of full scale experiments characterising how slot louvre systems with low hydraulic diameters perform within ventilation strategies where mechanisms such as turbulent eddy diffusion play an important function. For example Kang investigated how different louvre ventilator angles installed in the windward face of a factory wall changed indoor velocity field and turbulence. They showed that louvre ventilator angle can increase the internal mean velocity and turbulence further away from the ventilation inlet. However it didn't consider shear induced flow and also used a double sided ventilator to direct the internal flow and also had a roof mounted exhaust point (Kang and Lee 2008). Nakanishi et al showed that the pressure loss characteristic varies significantly relative to louvre angle and the differential pressure was close to a quadratic function of impinging wind velocity at normal incidence (Nakanishi et al 2007). However different impinging wind incidence angles were not investigated, buoyancy wasn't included and the louver angle at air entry was flipped compared to the louvre system presented in this paper. Hughes et al have also looked at the effect of external louvre angle on the ventilation performance of the windcatcher system and have demonstrated that the louvres follow aerodynamic stall theory (Hughes and Ghani 2010).

\section{EXPERIMENTAL SETUP}

A total of 25 full scale ventilation rate tests from the retrofit space for different component opening configurations were compared to 13 tests in a control space in the existing building with dynamically similar characteristics. Ventilation components tested are described in section 3. Experimental measurements were recorded using a $\mathrm{CO}_{2}$ tracer gas decay technique with a linear regression 
technique applied to spatially averaged and normalised concentration values. 2 NDIR sensors were used in the test space with measured values adjusted for background $\mathrm{CO}_{2}$ levels. All tests were completed under normal operating mode for the ventilation system resulting in the inclusion of effects from some complex geometry at the openings and two opening apertures serving the retrofit test space each time. Figure 1 outlines the physical geometry of the control space room and the retrofit space room as well as NDIR sensor locations and vertical temperature measurement locations; Figure 2 shows the two envelopes at different locations of the same building, while Table 1 includes a summary of test conditions. A detailed summary of the experimental setup and test conditions for both retrofit space and control space has recently been published by the authors and is not repeated here (O'Sullivan and Kolokotroni, 2014).
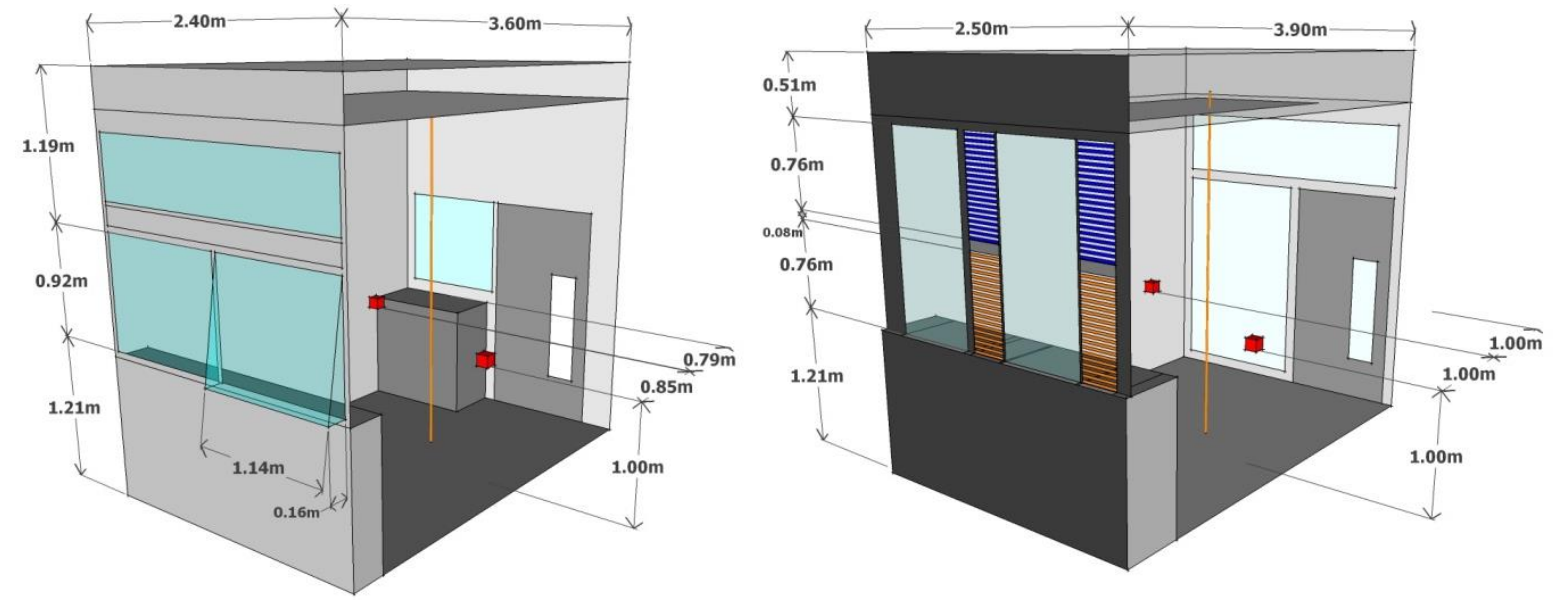

Figure 1: Control Space (CS.01) geometry details (left) and Retrofit space geometry details (right) with configuration RS.02 shown in Orange, configuration RS.03 shown in blue with RS.04 being both RS.02 and RS.03 combined.

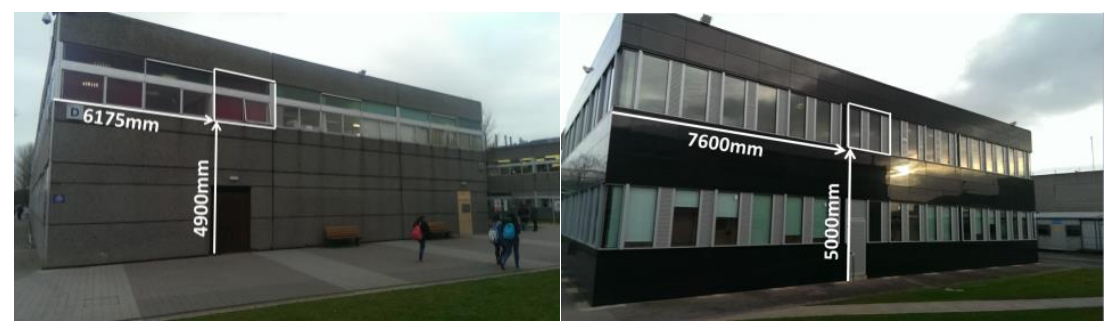

Figure 2: Control Space envelope (left) and retrofit space envelope (right) with dimensions of room locations at CIT, Cork, Ireland.

Table 1: Schedule of experimental tests and conditions

\begin{tabular}{lcccccc}
\hline \multicolumn{1}{c}{ Config. } & $\begin{array}{c}\text { No of } \\
\text { tests }\end{array}$ & $\begin{array}{c}\text { Range of test } \\
\text { durations }\end{array}$ & $\begin{array}{c}\text { Average } \\
\text { Conc. } \\
\text { uniformity }\end{array}$ & $\begin{array}{c}\text { (Ave) Start } \\
\text { PPM Range } \\
\text { (Adjusted.) }\end{array}$ & $\begin{array}{c}\text { (Ave) End } \\
\text { PPM Range } \\
\text { (Adjusted.) }\end{array}$ & $\begin{array}{c}\text { Average } \\
\text { B.G. PPM } \\
\text { (\%) }\end{array}$ \\
\hline CS-1.0/M & 13 & $24-90 \mathrm{~min}$ & $2.57 \%$ & $3181-6203$ & $175-1214$ & 10.3 \\
RS-2.0/M & 6 & $26-60 \mathrm{~min}$ & $1.51 \%$ & $3538-5431$ & $364-1481$ & 12.3 \\
RS-3.0/A & 6 & $31-60 \mathrm{~min}$ & $4.46 \%$ & $3511-5051$ & $703-1327$ & 13.4 \\
RS-4.0/A/M & 13 & $30-161 \mathrm{~min}$ & $2.37 \%$ & $3647-4746$ & $212-1067$ & 13.0 \\
\hline CS=Control Space; RS= Retrofit Space; $M=$ Manual; A=Automated with manual override
\end{tabular}

CS=Control Space; $R S=$ Retrofit Space; $M=$ Manual; $A=$ Automated with manual override 


\section{VENTILATION COMPONENT DETAILS}

\subsection{Slot louvre ventilation system (Configuration/RS.02, RS.03, RS.04/Figure 1-Right)}

The installed slot louvre system has a net $50 \%$ free open area for airflow and overall structural opening dimensions are $0.30 \mathrm{~m}(\mathrm{w}) \times 1.60 \mathrm{~m}(\mathrm{~h})$ with a net opening area of $0.102 \mathrm{~m}^{2}$ (2 openings at low level and 2 openings at high level in the test space). On the internal side of the slot louvres there are automated higher level insulated doors and manual lower level insulated doors providing different control mechanisms. The ventilation system forms part of an externally applied retrofit fenestration module supplied with two glazed sections and two ventilation sections. The louvres are manufactured in anodized aluminium alloy 6063-T6 with a resulting smooth surface finish, see Figure 3. Each of the ventilation openings has 17 airflow slots across the louvre bank. Taken individually the louvre slots have an extremely low porosity at $0.057 \%$. Table 2 summarises key information regarding the slot louvre system.
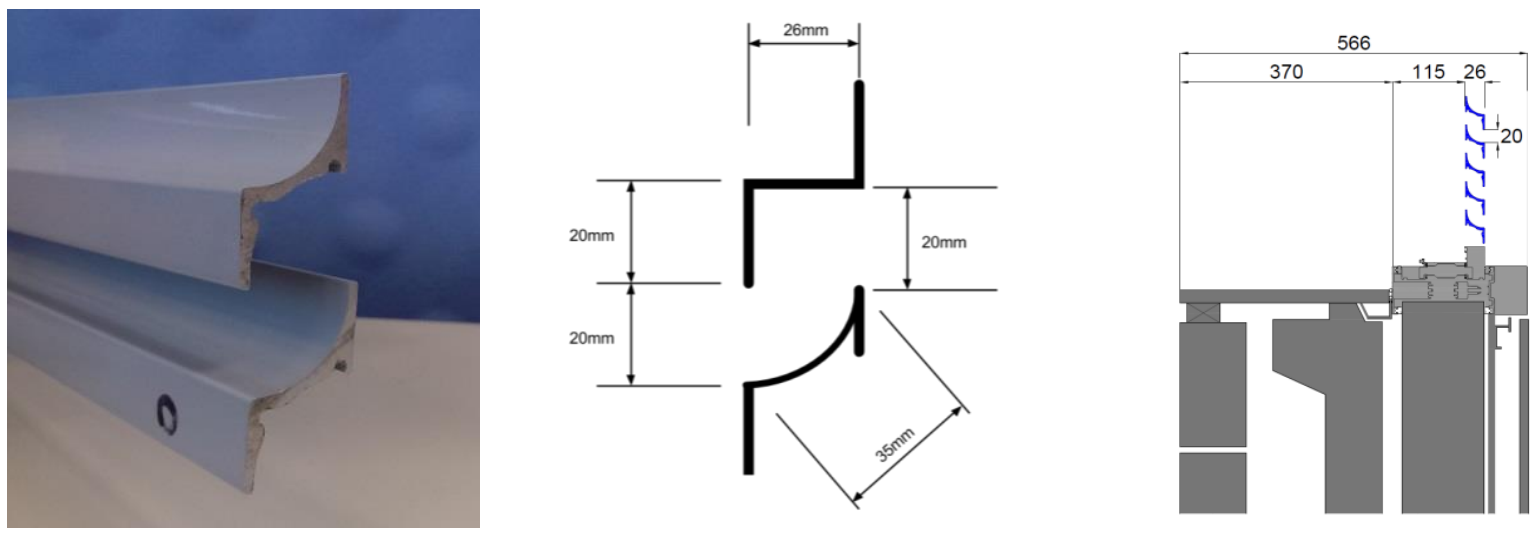

Figure 3: Slot louvre details (left) sample louvre profile, (middle) dimensions (right) installation section

\subsection{Top hung outward opening window (Configuration - CS.01/Figure 1-left)}

The control space ventilation component consists of an outward opening top hung window unit. This was used as a basis for comparison of time average ventilation rates and ventilation unsteadiness during tests with the slot louvre system. Details are summarised in Table 1 and in (O'Sullivan and Kolokotroni. 2014). There appears to be limited data available on full scale performance of this type of window in the literature. Recently Grabe presented work characterising flow resistances for different window types (Grabe 2013). Based on laboratory tests of buoyant flow through the openings he proposed different resistances for inlet and outlet areas where openings were asymmetrical (i.e. a combination of triangular and rectangular). He proposed an empirical law between flow resistance and total opening area for awning windows similar to the one used in the control space. Based on this we have estimated a $C_{d}$ using equation (1) below:

$$
C_{d}(c s)=(\xi)^{-1 / 2}=\left(0.0018 \cdot A_{t(c s)} \cdot 1000-0.1351\right)^{-1 / 2}=0.422
$$


O'Sullivan PD and Kolokotroni M (2016). Non dimensional analysis and characterisation of driving forces for a single sided slot louver ventilation system. International Journal of Ventilation, Vol 14, 4, (doi:10.1080/14733315.2016.11684091)

Table 2: comparison of purpose provided ventilation opening types in CS \& RS

\begin{tabular}{lccc}
\hline Parameter & CS & RS & Units \\
\hline Plain structural opening dimensions (W x H) & $0.92 \times 1.14$ & $0.30 \times 1.60$ & $\mathrm{~m}$ \\
Total opening area $\mathrm{A}_{\mathrm{t}}$ & 0.32 & 0.42 & $\mathrm{~m}^{2}$ \\
Porosity & 0.18 & 0.057 & $(\%)$ \\
Total opening "wetted" perimeter & 5.96 & 0.99 & $\mathrm{~m}$ \\
Hydraulic diameter $\left(\mathrm{d}_{\mathrm{h}}\right)\left(\mathrm{A}_{\mathrm{t}}\right.$ \& based on "wetted" perimeter) & 0.214 & 0.02 & $\mathrm{~m}$ \\
Aspect Ratio $\left(\mathrm{L} / \mathrm{d}_{\mathrm{h}}\right)$ & $1.070^{*}$ & 1.075 & $(-)$ \\
Opening type (categories according to Etheridge 2011) & short & short & $(-)$ \\
\hline
\end{tabular}

*Note: length dimension for CS measured along perimeter of opening window section

\section{CHARACTERISING DRIVING FORCES}

\subsection{Previous work analysing driving forces}

The mechanisms that produce airflow in single sided ventilation are generated through varying combinations of wind and buoyancy forces acting at the opening. Depending on wind direction the dominant mechanisms are either from a pulsating flow due to pressure difference at the opening, turbulent diffusion through a mixing layer at the opening plane or a combination of both. When due to buoyancy forces alone, the flow will be bidirectional with a neutral pressure at the opening mid height point. The temperature difference at the opening results in a buoyancy effect that produces a stable airflow exchange. However, at low wind speeds and a leeward direction the effective enveloped temperature has been shown to be reduced due to a recirculation zone counteracting buoyancy effects resulting in air change rates lower than in the absence of wind (Caciolo et al 2013). When wind is normal to the opening plane a pulsation airflow effect will dominate increasing compression of the air mass but not necessarily adding to ventilation rate. Cockroft and Robertson suggested that $37 \%$ of the volume flowrate across the opening due to pulsation will contribute to an air change rate (Cockroft and Robertson. 1976). The local wind speed at the opening is very much dependant on wind direction due to changes in flow patterns along the envelope given different wind directions. Larsen shows how air change rate depends on wind direction with effect more pronounced at low wind speeds and the dominating force differs between wind speed and $\Delta \mathrm{T}_{\mathrm{ie}}$ depending on the ratio between these forces and the wind direction (Larsen and Heiselberg 2008). When working with steady envelope flow models an empirical power law, equation (2) below, has been used to describe flow in situations where the geometry is complex and flow is assumed as being independent of $R e$.

$$
Q=\alpha \Delta p^{\beta}
$$

When flow is best predicted using $\beta=1.0$ we have a linear relationship with the constant $b$ derived empirically although according to Etheridge and Sandberg (Etheridge and Sandberg 1996) it can have a physical meaning:

$$
Q=b \Delta p
$$

When envelope flow models are based on orifice flow theory, we have $\beta=0.5$ and for the flow due to buoyancy alone case, employing a still air discharge co-efficient $C_{d}$, using the ideal gas law to substitute temperature for density, we have: 


$$
Q=\frac{1}{3} C_{d} A\left(\frac{\Delta T g H}{T}\right)^{1 / 2}
$$

Within these two extremes $\beta$ can have an influence on the ability of a given model to correctly predict ventilation rates obtained experimentally as shown for example by Sharples et al (Sharples and Chilengwe 2006). In addition to buoyant flows a number of semi empirical models have attempted to account for contributions from wind effects. Warren and Perkins (Warren and Parkins 1985) proposed 2 separate correlations for buoyancy and wind effect, taking the larger of the two to quantify ventilation rate. Dascalaki (Dascalaki et al 1996) proposed an alternative correlation to take account of wind effects. See also for example (Crommelin and Vrins. 1988), (De Gids and Pfaff. 1976), (Wang and Chen 2012). When studying permutations of contributing forces for ventilation rate tests Warren used the relationship between a dimensionless ventilation parameter, Flow Number $F_{R}$, and an adjusted Archimedes Number, $A r^{0.5}$. The purpose of the Warren plot is to separate out the data dominated by buoyancy effect. Warren plots have been used by researchers to analyse air change rate data, for example see (Warren and Parkins 1985) (Van Der Mass. 1992), (Caciolo et al 2011). Archimedes Number, $A r$, is used as a measure of the relative magnitudes of the buoyancy (gravity) forces and the momentum (inertial) forces acting on elements of fluid. This ratio can be expressed in (5) where $L$ is a characteristic height.

$$
\frac{\Delta \rho g L}{P_{w}}
$$

For dynamically similar flows substituting $\rho v^{2}$ for total wind pressure, $P_{w}$, one obtains a dimensionless parameter which is basically the same as that known as $A r$ (Etheridge, 2011):

$$
A r \equiv \frac{\Delta \rho g L}{\rho v^{2}}
$$

As mentioned above the ratio $\Delta \rho / \rho$ can be replaced with $\Delta T / T$ for cases of interest here. For large $A r$ values buoyancy forces will dominate. $A r^{0.5}$ can be defined in (7) where $H$ is the opening height in question.

$$
A r^{0.5}=\left(\frac{\Delta T_{i e} g H}{\bar{T}_{i} v_{w}{ }^{2}}\right)^{0.5}
$$

The ventilation parameter, $F_{R}$, is a practical dimensionless number based on a reference wind velocity to describe wind induced ventilation. Generally where flow is buoyancy dominated $F_{R}$ should approach the asymptote defined by $F_{t h}$ in equation (9). When wind dominates $A r^{0.5}$ tends to zero and $F_{R}$ becomes independent of $A r^{0.5}$. For parallel flows, according to work by Warren (Warren and Parkins 1985$), F_{R}$ should be approximately constant at $0.03 . F_{R}$ can be defined as:

$$
F=\frac{Q}{A_{e} v_{w}}
$$

Plotting these vales for each test allows an interpretation of the influence wind forces have on the buoyancy effect, either assisting or opposing its contributing force.

\subsection{Definition of $\boldsymbol{F}_{t h}$ asymptote for ventilation components}

Dimensional analysis using the Warren plot is predicated on the correct selection of the asymptote through the origin defining flow number due to buoyancy alone, $F_{t h}$, described in equation (9). 


$$
F_{t h}=\frac{Q}{A_{e} v_{t h}^{2 \beta}}=\frac{1}{3} C_{d} A r^{\beta}
$$

The gradient of this asymptote is sensitive to correct selection of both the still air discharge coefficient, $C_{d}$ and the exponent used in the power law relationship for pressure and flow (i.e. $\beta=0.5$ for orifice flow). $C_{d}$ is an important parameter for a ventilation opening as it depends on the geometry of the opening and the Reynolds number, $R_{e}$ of the flow, and is normally taken as 0.61 for a flush faced sharp edged orifice. Various research studies have considered the effect on $C_{d}$ of different opening types and their geometry, shape and porosity under wind driven flow (Karava et al 2004) (Heiselberg et al 2001), while other studies have concentrated on the effects of wind in terms of direction and the effects of dynamic pressure (Chiu and Etheridge 2007). Caciolo et al (Caciolo et al 2011) used a $C_{d}$ value of 0.6 to describe the flow characteristic when calculating $F_{t h}$ for various open window geometries while a $C_{d}$ of 1.0 is used in (Dascalaki et al 1996). The work by Grabe is outlined in section 3.2 (Grabe 2013; von Grabe et al 2014). Both Pinnock (Pinnock 2000) and Sharples et al (Sharples and Chilengwe 2006) have carried out experimental work considering the use of alternative exponent values in the power law equation when dealing with the buoyancy alone case and slot louvres respectively. Pinnock proposed $\beta=0.6348$ and Sharples suggested $\beta=0.9301$. As indicated in section 4.1 a comparison of the value of $F_{R}$ with $F_{t h}$ using the warren plot indicates whether the non-dimensional ventilation rate is buoyancy dominant or otherwise. $F_{t h}$ can be said to be a function of three primary parameters based on equation (9) summarised in equation (10) as:

$$
F_{t h}=f\left(A r, C_{d}, \beta\right)
$$

We tested the sensitivity of these parameters on the buoyancy asymptote, $F_{t h}$, and the resulting modal shift from wind dominant to buoyancy dominant $F_{R}$. While the physical relationship between $A r$ and $\beta$ is not clearly defined in the literature for values other than $\beta=0.5$ (with $A r$ for the cases of interest defined based on Bernoulli flow) it was still worthwhile to include $A r^{\beta}$ as a linear coefficient in testing the sensitivity of $F_{t h}$ to the results. Using a sample size $N=38$ based on experimental test data we divided the measured distribution of all $F_{R}$ into $q$ equally sized quantiles with the kth quantile equal to $k / q$. For this study we set $q=2$, took the smallest $F_{R}$ observation to correspond to a probability of $0(0 / 2=0)$, the largest observation to a probability of $1(2 / 2=1)$, giving us the 0 , 50th \& 100th percentiles from the measured data. We then selected matching $A r$ values for each $F_{R}$ based on the measured data. This resulted in a manageable parameter space and gave realistic ranges for combinations of $F_{R}$ and $A r$. The range of values chosen for parameter $x_{i}$ in equation (9) is the set defined using the cardinality and interval in equation (11). $i=1$ for $C_{d}, 2$ for $\beta$ and 3 for $A r$.

$$
\begin{gathered}
\left|x_{1}\right|=8, \quad\left\{x_{1, j} \in \mathbb{R} \mid 0.4 \leq x_{1, j} \leq 0.9\right\} \\
\left|x_{2}\right|=6, \quad\left\{x_{2, j} \in \mathbb{R} \mid 0.5 \leq x_{2, j} \leq 1.0\right\} \\
\left|x_{3}\right|=4, \quad\left\{x_{3, j} \in \mathbb{R} \mid 0.005 \leq x_{3, j} \leq 0.12\right\}
\end{gathered}
$$

Each combination $c$, equates to a value of $F_{t h}$ with all possible combinations of parameters calculated from the cardinality of the Cartesian product of all sets, in this case $n=3$.

$$
X=\left|x_{1}\right| \cdot\left|x_{2}\right|, \cdots,\left|x_{n-1}\right|,\left|x_{n}\right|
$$

This configuration of parameters resulted in 192 different possible combinations. Each $F_{R}$ value was compared with only those $F_{t h(c)}$ values that had the same $A r$ (i.e. $48 F_{t h(c)}$ values for each of the $4 A r$ 
values selected), as would be on the Warren plot. An error value for each combination, $e_{c}$, shown in equation (13) was calculated giving the difference between $F_{R}$ and a baseline, standard asymptote, denoted $F_{t h(b)}$, (based on $C_{d}=0.61$ and,$\left.\beta=0.5\right), \Delta F_{b}$, and $F_{R}$ and the particular $F_{t h(c)}$ for the combination under consideration, $\Delta F_{c}$.

$$
e_{c}=\Delta F_{b}-\Delta F_{c}
$$

For example lowering $C_{d}$ reduces the apparent slope of the asymptote, reducing $\beta$ actually reduces $A r^{\beta}$ values shifting $F_{R}$ values towards the ordinate linearly resulting in an apparent reduction of the asymptote, both changes manifest as a modified $\Delta F_{c}$. Figure 4 presents values for $e_{c}$ for each of the various different combinations of $A r, C_{d}$ and $\beta$ at particular $F_{R}$ values. Each sub grid represents a particular $F_{R} / A r$ combination on the warren plot and the tiles within each sub grid are the $e_{c}$ values. For $F_{t h(c)}$ where $C_{d}=0.61$ and $\beta=0.5, e_{c}$ is always shown as zero. On the warren plot, as $F_{t h(c)}$ passes through $F_{t h(b)}$, with both asymptotes co-located, $e_{c}$ reduces to zero, increasing again as $F_{t h(c)}$ moves away from $F_{t h(b)}$ towards $F_{R}$. $e_{c}$ continues to increase without a modal shift until it passes through $F_{R}$ a critical point where there is then a modal shift and is represented with a sign change in Figure 4.

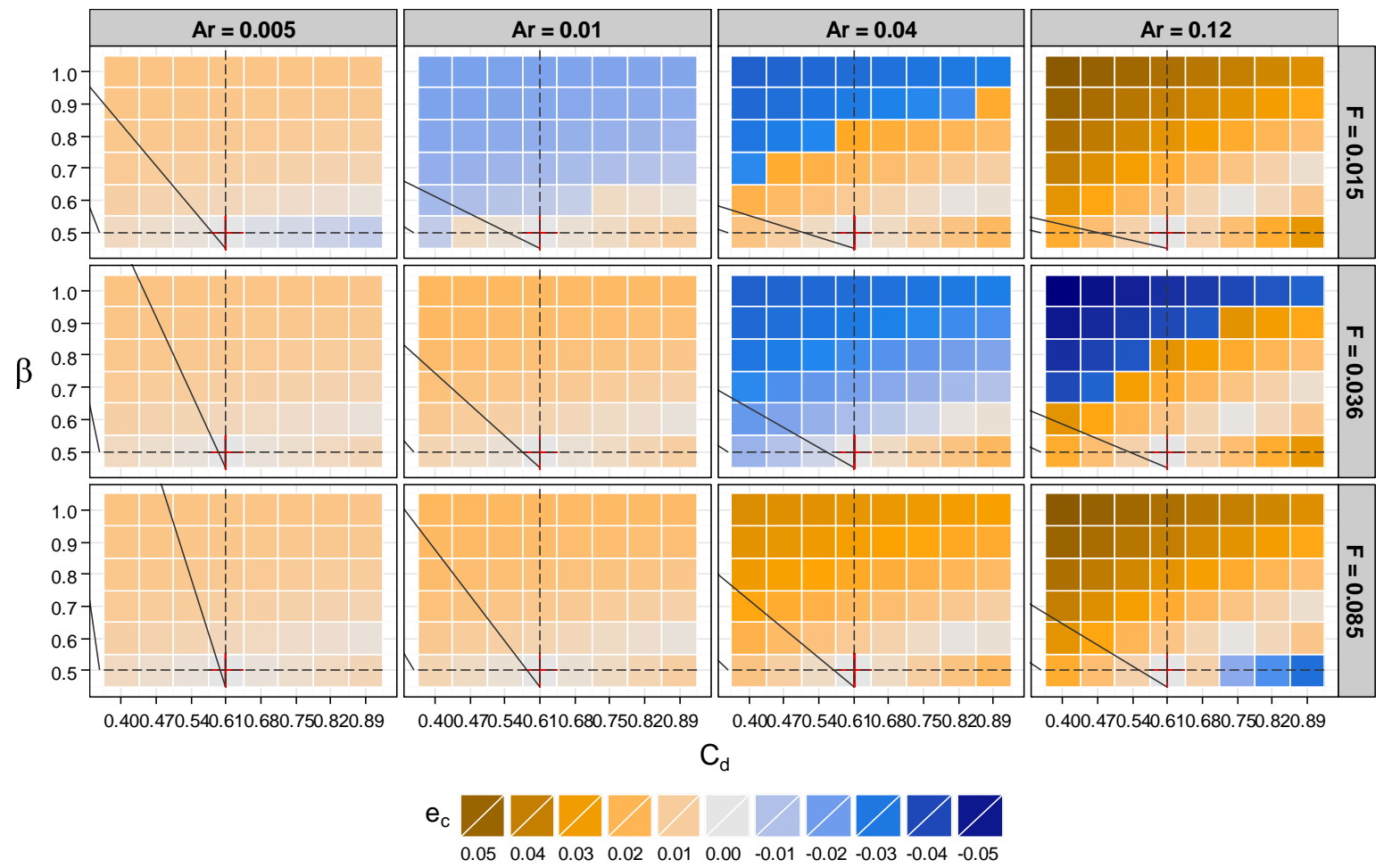

Figure 4: $e_{c}$ for all $\boldsymbol{X}$ combinations grouped according to $F_{R}$ (vertical axis) and $\mathrm{Ar}$ (horizontal axis). Negative $e_{c}$ values represent a modal shift with $F_{t h(c)}$ passing through $F_{R}$ giving the critical $C_{d} / \beta$ combination causing change in contribution from wind forces. Magnitude of $e_{c}$ represents scale of modal shift.

In considering Figure 4, at low $A r$ there is little sensitivity to a modal shift from wind dominant to buoyancy dominant conditions. At low $A r$ test conditions are usually wind dominant with high $F_{R}$ values. At $F_{R}=0.015$ there is a modal shift at $C_{d}>0.61$ showing high sensitivity. At $0.01<A r<$ 0.04 no modal shifts appear for almost all $C_{d}$ at $\beta=0.5$. Only as $\beta$ increases do we see results with 
high sensitivity to input parameters. At $\beta=0.5$ sensitivity is present at $F_{R}=0.036$ for $C_{d}<0.61$ with modal shifts taking place for these parameters, in this instance shifting from buoyancy to wind dominant conditions. A number of test results presented in this paper are in this range. At $F_{R}=0.085$ and $A r=0.12$ there is modal shifts at $C_{d}>0.75$ but only at $\beta=0.5$ and very few test results had these conditions. In summary there appears to be some sensitivity to $C_{d}$ for the tested $F_{R} / A r$ ranges but this is neither systematic throughout and generally low at $=0.5$. At $A r<0.04$ values, where a lot of the measured data is situated, there is little evidence of modal shifts, irrespective of the magnitude of $F_{R}$. At mid-range $A r$ and with $F_{R}$ values reported by Warren (0.025-0.035), it appears sensitivity to the physical geometry of the opening exists when interpreting the contribution from wind forces.

\subsection{Selection of $C_{d}$ for analysis}

Notwithstanding the analysis above the value selected for $C_{d}$ for the control space window opening to facilitate analysis is 0.422 and is largely based on Von Grabe (Grabe 2013). A $C_{d}$ value of 0.55 is assumed for RS.03. The slot louvre system used here is a flush faced sharp edged orifice at the inlet and flow is likely unidirectional through the individual slot openings. There is a length component of the louvre in a circular shape (see Figure 3) that might promote some flow reattachment allowing viscous forces and a boundary layer to develop, reducing the flow separation that normally results in $C_{d}$ being independent of $R e$. However, for the purposes of establishing a $C_{d}$ value under buoyancy alone conditions 0.61 may be a little low but acceptable for RS.04 and RS.02 for the purposes of initial analysis. The RS.03 configuration has the combined effect of slot louvre and inward opening ventilation door due to its restricted opening angle and a $C_{d}$ probably lower than 0.61 as a result.

\section{TEST CONDITIONS}

Figure 5 presents polar frequency plots of wind speeds distributed according to wind direction for each test configuration summarised in Table 3 of (O'Sullivan and Kolokotroni. 2014). An analysis of wind data for each test using directional statistics (Mardia. 1972) shows that the mean resultant length of direction vectors, a measure of "concentration" for circular data such as wind direction, were in many instances close to 1.0 with low dispersion of wind orientation during individual tests. This suggests that wind direction was consistent during a given test and the resulting analysis can assume to represent the effects from flow phenomena present for this type of orientation relative to the ventilation opening. We have taken Parallel flow to occur between wind directions of $347.5^{\circ}-22.5^{\circ}$ $\& 157.5^{\circ}-202.5^{\circ} .270^{\circ}$ wind direction is normal to the ventilation opening.
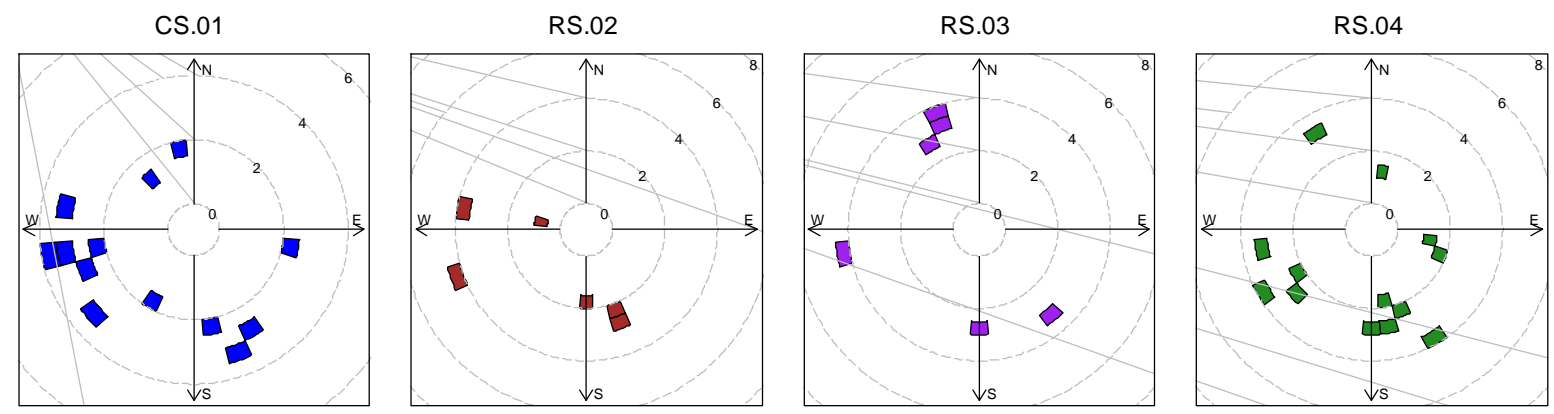

Figure 5: Polar frequency plots for each set of tests according to configuration 


\section{RESULTS \& ANALYSIS}

Figure 6 summarises variability in recorded mean ventilation rates for each test configuration with mean values shown as circular points. Single sided ventilation strategies rely on a number of low and high frequency unsteady flow phenomena relating to wind pressure, gustiness and turbulence. Tracer decay rates were measured at a frequency of $1 \mathrm{hz}$ during each test and Figure 7 presents recorded mean ventilation rates as a function of mean wind direction and Figure 8 as a function of wind speed, grouped according to test configuration. The colour scale for data points indicates magnitude of envelope temperature difference for each test while the data point size indicate the amplitude of concentration fluctuation, $\sigma_{c}$, which is based on the estimate of error in prediction from the regression model fitted to the normalised concentration decay, $C_{N}$, to determine the mean ventilation rates (O'Sullivan and Kolokotroni. 2014). This is taken as an indicator of the level of unsteadiness present during each test.

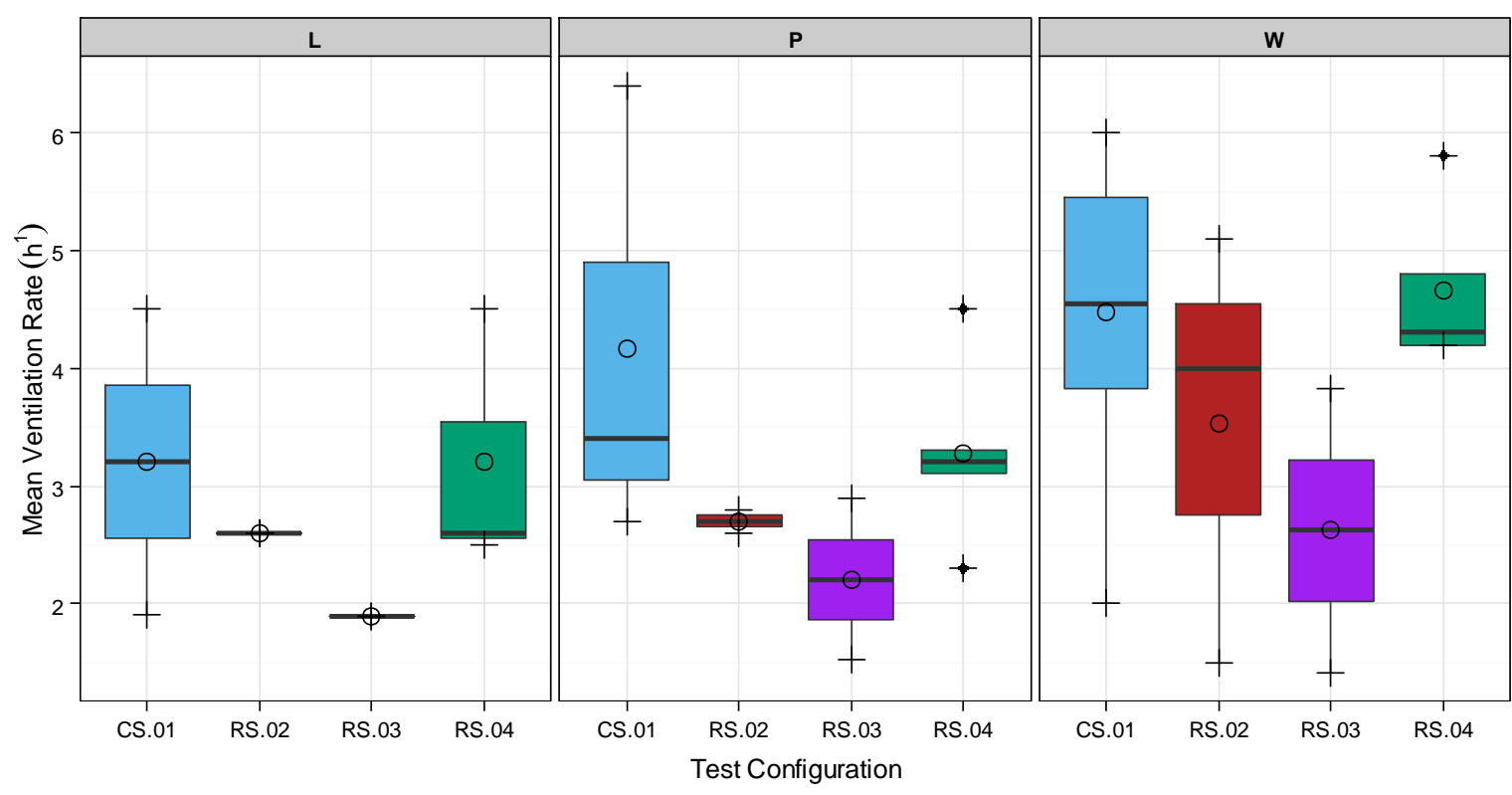

Figure 6: Boxplot of mean ventilation rates $\left(h^{-1}\right)$ for each configuration grouped according to reference wind direction, (Leeward, Parallel, Windward)

\subsection{Influence of buoyancy and momentum forces}

Considering Figure 7 in all configurations the highest recorded mean ventilation rates generally occurred with $\Delta T_{i e}>4^{\circ} \mathrm{C}$ and a windward wind direction. Lower mean ventilation rates generally occurred with low $\Delta T_{i e}$ which also coincided with leeward conditions. Parallel wind directions show less defined patterns. This suggests an important relationship exists between the magnitude of $\Delta T_{i e}$ and the wind direction. Low $\Delta T_{i e}$ generally resulted in lower ventilation rates for low opening height RS.02 \& RS.03 while some CS.01 \& RS.04 tests have mean ventilation rates higher than $4.0 \mathrm{~h}^{-1}$ even at $\Delta T_{i e}<4.0^{\circ} \mathrm{C}$. Figure 7 suggests that where the wind direction is not approximately normal to the surface then it is more likely to have lower ventilation rates even at relatively high $\Delta T_{i e}$ values. Results suggest that leeward and parallel flows at the opening are more likely to generate phenomena that will oppose buoyancy forces, for example turbulent diffusion reducing the effective temperature difference through mixing (Caciolo et al 2011). RS.04, the largest opening height, shows a more pronounced trend between mean ventilation rate and wind direction while CS.01 also shows some agreement in this regard. Furthermore $\sigma_{c}$ is consistently larger under windward wind direction potentially showing a correlation with pulsating flow from wind gustiness and resulting air 
compressibility rather than turbulence mixing. This underlying trend for slot louvered systems is something that has not been hugely investigated in the literature. Furthermore when considering Figure 8 the data suggests a co-dependency exists between mean ventilation rates, $\Delta T_{i e}$ and wind speed for the RS configurations but this same trend isn't present in the CS dataset. In fact it suggests that wind speed contribution is less important for the outward opening window type and $\Delta T_{i e}$ and wind direction are more important to predicting the resulting ventilation characteristics. Compared to the CS.01 configuration the reduced aspect ratio of the slot louvre system seems to reduce the effects of phenomena such as eddy penetration, particularly during windward conditions permitting buoyancy forces to better establish.

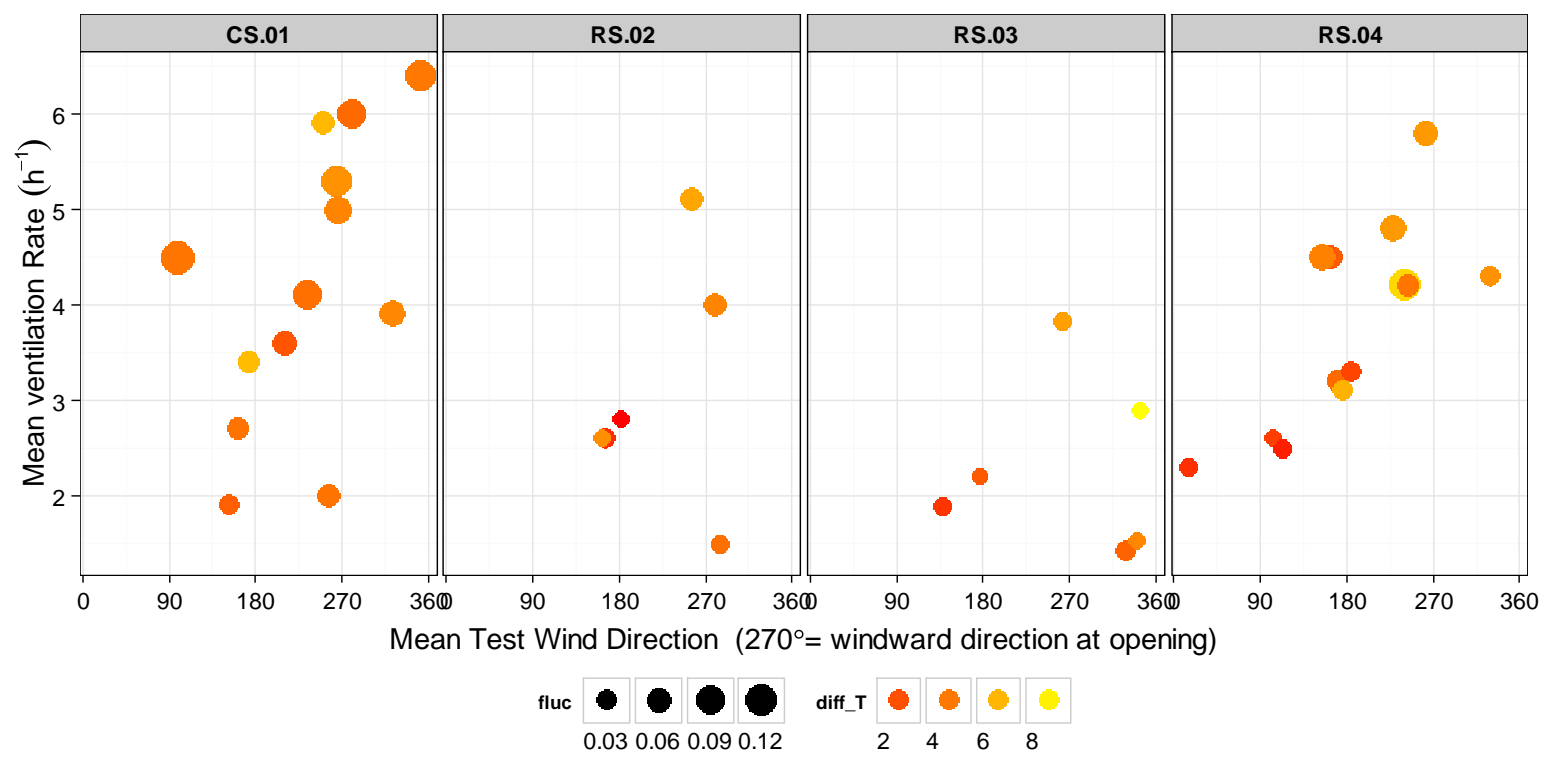

Figure 7: scatterplot of mean ventilation rates $\left(h^{-1}\right)$ vs wind direction, (classified with $\Delta T_{i e} \& \sigma_{c}$ )

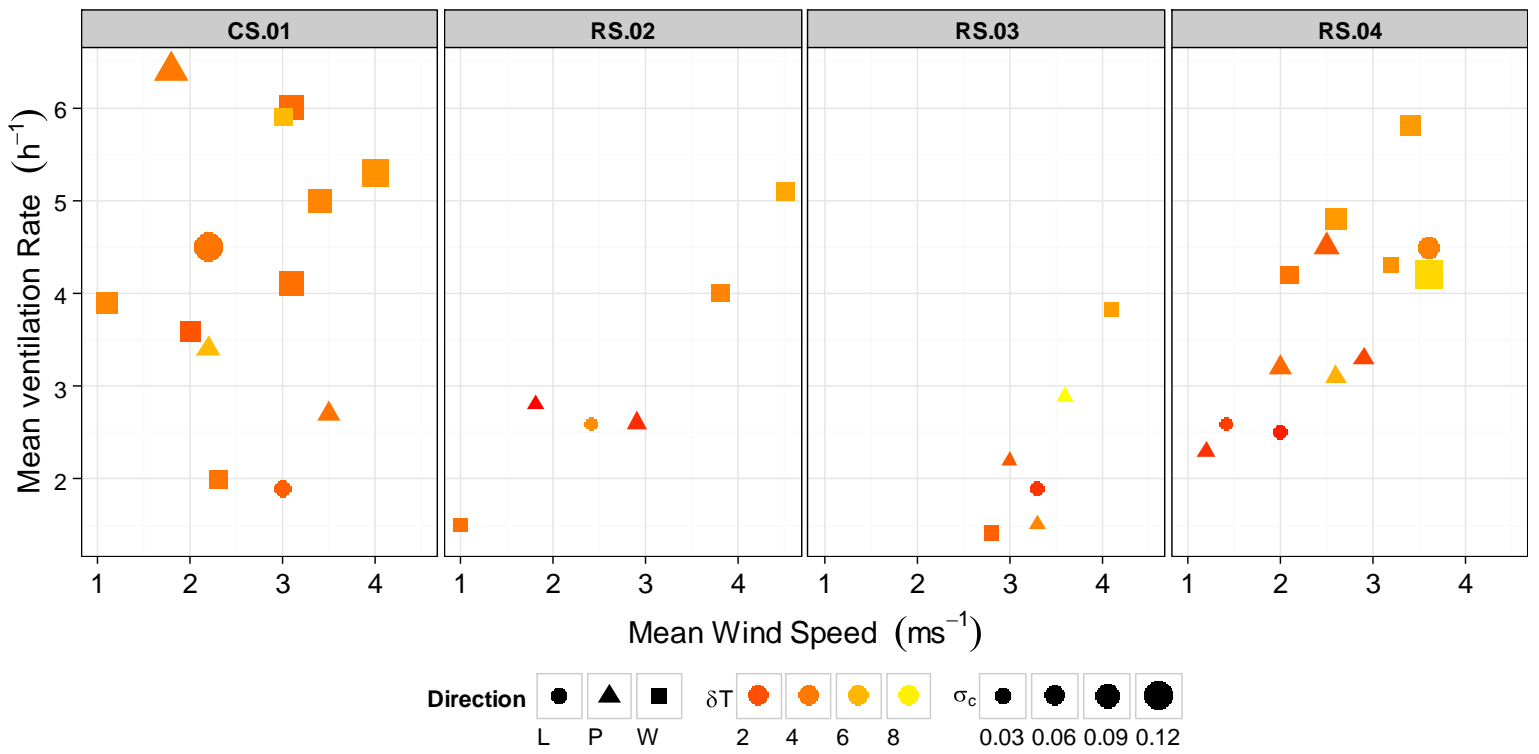

Figure 8: scatterplot of mean ventilation rates $\left(h^{-1}\right)$ vs $v_{w}$ (classified with $\Delta T_{i e} \& \sigma_{c}$ )

\subsection{Ventilation rate characteristics}

While it is difficult to draw any clear quantitative conclusions regarding high frequency fluctuating phenomena when examining time averaged test data, the concentration fluctuation parameter, $\sigma_{\mathrm{c}}$ 
(based on $0.1 \mathrm{hz}$ arithmetic averages of readings taken at $1 \mathrm{hz}$ ), can still give a measureable indication of the overall unsteadiness present in a ventilated space during a tracer decay test. The cause of this un-steadiness however, can be due to several factors: pulsation flow, penetration of eddies (depending on sensor location), and static or molecular diffusion. 10 of the 13 CS.01 window opening tests exhibited unsteadiness at the upper end of all recorded $\sigma_{c}$ values. These appeared to happen primarily under windward wind directions and across all wind speeds. There was no visible correlation with wind speed and most of these high $\sigma_{\mathrm{c}}$ instances had $\Delta \mathrm{T}_{\mathrm{ie}}>5.0^{\circ} \mathrm{C}$ although these appeared wind dominant according to the non-dimensional analysis in section 6.3 below. This would suggest that the fluctuating component of the ventilation rates is more amplified when wind is normal to the outward opening window case. This may be due to the nature of flow impingement with the window obstructing entry resulting in increased localised turbulence. The highest fluctuation value for parallel flow in CS.01 happened with one of the lowest average test wind speeds $\left(1.8 \mathrm{~ms}^{-1}\right)$ while the two other parallel flow tests showed lower unsteadiness profiles with lower non-dimensional $F$ values suggesting that with parallel flow and an outward opening window fluctuating components of ventilation rate are less pronounced and buoyancy driven flow is able to better establish. This may be due to the fact the opening section of the window does not obstruct parallel flow at the boundary layer of the structural opening. More parallel flow tests are needed however before this is conclusive. In the slot louvre system only RS.04 exhibits tests with significant unsteadiness and all these tests occurred at a windward wind direction and higher wind speeds with a more noticeable trend visible in Figure 7 and Figure 8. Higher $\sigma_{\mathrm{c}}$ values are associated with higher ventilation rates in RS.04 suggesting the importance of dynamic phenomena such as wind gustiness to single sided ventilation rates even for slot louvre systems. These also generally occurred at windward wind directions. Ai and Mak (Ai and Mak 2014) have shown that for plain openings velocity and pressure fields are relatively stable for windward wind directions and the resulting unsteadiness is mainly associated with a large impinging mean flow rather than turbulent exchange. This would suggest a more likely correlation of $\sigma_{c}$ with the pulsating flow of the wind than turbulent exchanges at the opening for results presented here. For RS.03 \& RS.02, irrespective of wind direction fluctuation parameters were always low as were ventilation rates although a trend existed with increasing wind speeds.

\subsection{Non dimensional analysis}

Figure 9 presents Warren Plots for CS \& all RS configurations. Figure 10 presents individual Warren Plots for each cardinal wind direction. The purpose of the different plots is to investigate trends that relate to opening geometry, test environment and associated combinations of buoyancy and momentum driving forces. Considering Figure 9 we see a comparable spread of $F$ values for both spaces with the retrofit $A r^{0.5}$ range extending further towards zero ordinate. $F$ values seem to display slightly higher dependency on $A r^{0.5}$ in CS.01 and RS.04. When the data is split according to RS opening configuration as shown, three different patterns emerge. RS.04, $\left(H_{\text {ope }}=1.60 \mathrm{~m}\right)$, shows a pattern of buoyancy dominant ventilation irrespective of the wind direction, which seems to agree with data in figure 7 where the highest RS.04 ventilation rates had high $\Delta T_{i e}$ values. Alternatively RS.03 has $H_{\text {ope }}=0.76 \mathrm{~m}\left(H_{\text {int }}=2.43 \mathrm{~m}\right.$ (above floor level)) and also has a potentially lower $C_{d}$ value than RS.02. It exhibits increased contributions from wind forces with similar $F$ values but consistently lower $A r^{0.5}$ values compared to RS.04. It appears that with a lower opening height buoyancy forces have less ability to establish irrespective of $\Delta T_{i e}$ resulting in lower $A r^{0.5}$ values and as a result $F$ values appear more independent of $A r^{0.5}$ in lower ranges suggesting the nature of the wind contribution is more important than its ratio to buoyancy forces. 


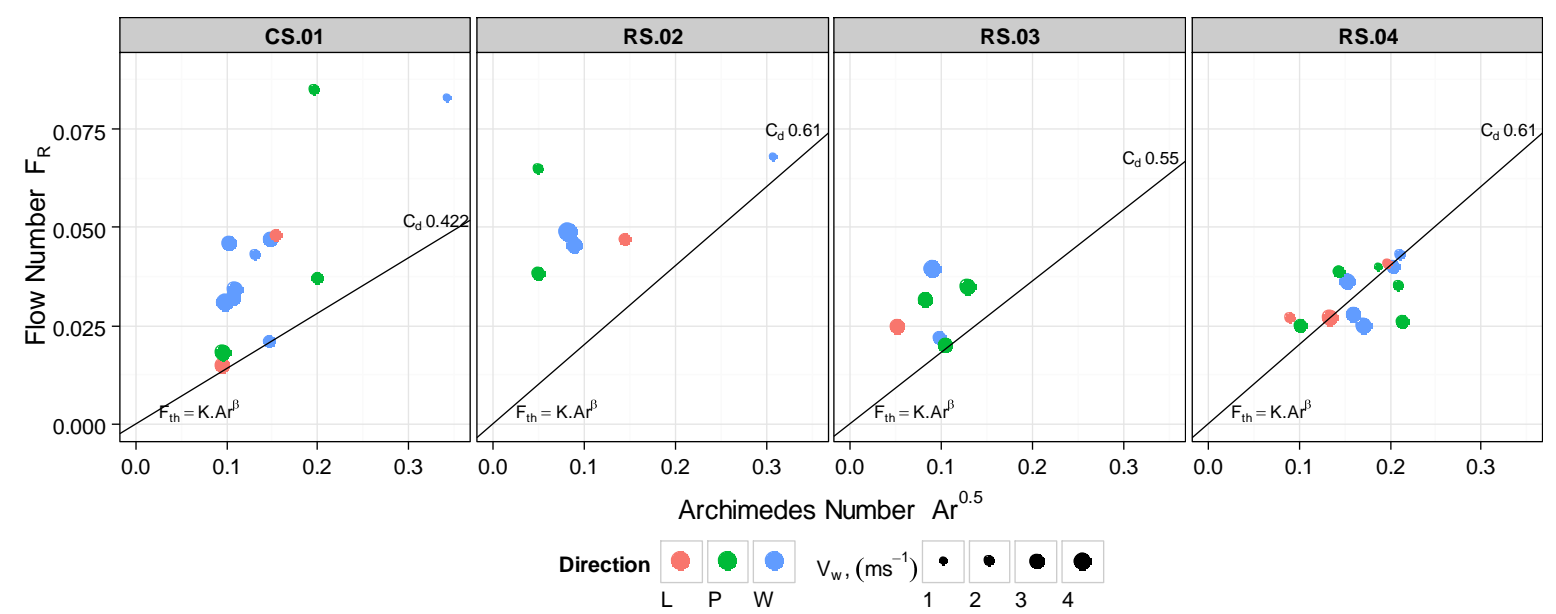

Figure 9: Warren Plot for all CS and RS configurations varying Fth asymptotes included as dashed lines

RS.02 $\left(H_{\text {ope }}=0.76 m\right)\left(\left(H_{\text {int }}=1.59 \mathrm{~m}\right)\right.$ has a greater internal door opening angle than RS.03 and a higher $C_{d}$ value. It exhibits the least dependency on buoyancy forces with nearly all tests showing wind dominant $F_{R}$ values. In general results suggest that for slot louvre systems the opening height, $H$, is an important factor modifying than the nature of the contribution from momentum forces (i.e. wind direction and magnitude) in determining whether or not they assist buoyancy forces. Considering figure 10 for RS configurations only, both parallel and windward wind directions show a pattern of reducing dependency of $F_{R}$ on $A r^{0.5}$ as its value tends to zero, a trend less pronounced with leeward tests. At low $A r^{0.5} F_{R}$ is a function of wind direction. At higher $A r^{0.5}$ values windward and parallel wind directions show a tendency of $F_{R}$ towards the $F_{t h}$ asymptote and the contribution from momentum forces are either diminished or generate conditions that favour buoyancy effects. In general the non-dimensional analysis indicates the contribution from momentum forces is a function of the overall structural opening height and location with this effect dependant on the ratio of momentum and buoyancy forces.

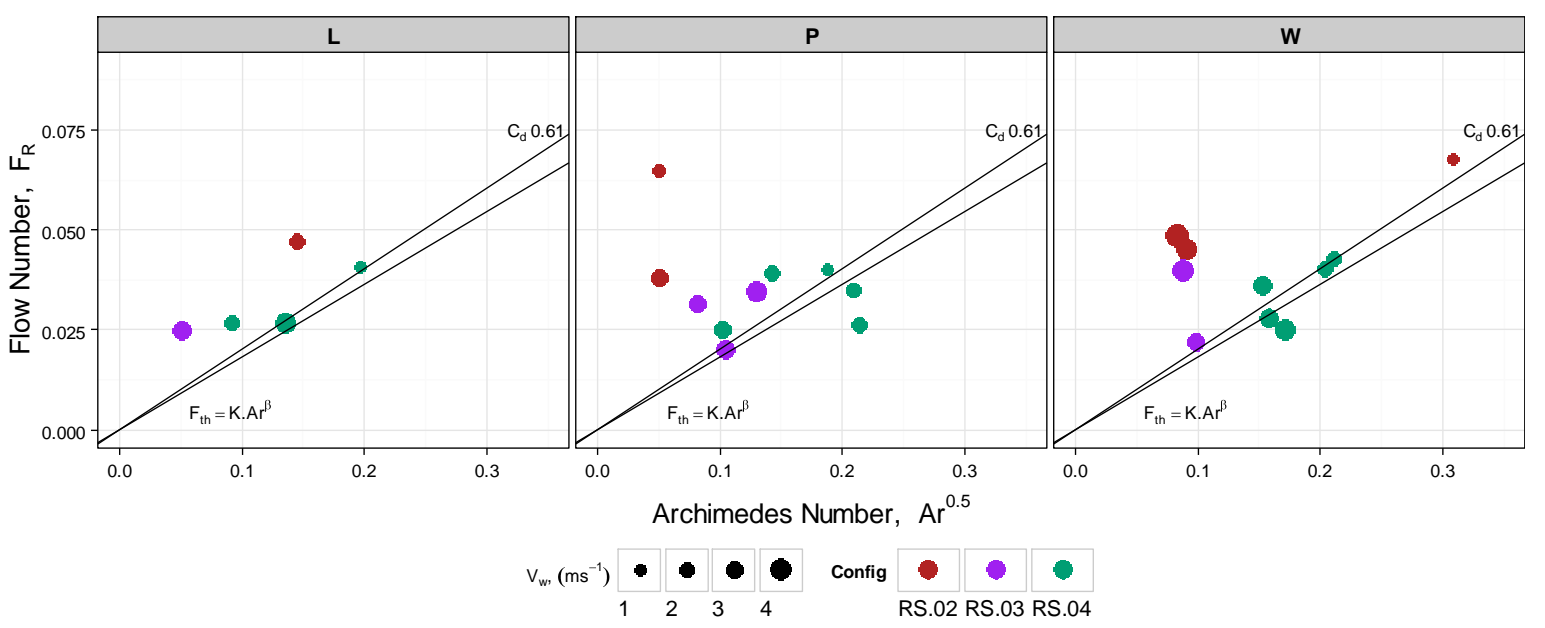

Figure 10: Warren Plots for wind directions

Overall these results suggest that at low $A r^{0.5}$ wind incidence angle becomes important in determining whether or not wind becomes dominant. Warren plot analyses suggest these are generally wind dominant with low $A r^{0.5}$ but they consistently exhibited low $\sigma_{c}$ values appearing counter intuitive. When comparing fluctuation rates for parallel wind directions in the RS configuration they 
are generally lower than windward wind directions. What is apparent from the data presented is the characteristic of ventilation rate is a function of the combination of opening geometry and wind direction. Furthermore the characteristics of the momentum forces (magnitude and direction) in turn influence the nature of ventilation and the resulting effect buoyancy forces will have. We have shown how mean ventilation rates depend on wind direction even for complex geometries such as slot louvers agreeing with findings from (Larsen and Heiselberg 2008) and furthermore the relative importance of this is also function of opening geometry and $A r^{0.5}$. It may not be sufficient to only consider $\Delta T_{i e}$ when investigating this effect.

\section{CONCLUSIONS}

This paper investigated the combined effect of buoyancy and momentum forces for slot louvre systems and has shown the magnitude and range of $A r^{0.5}$ to be dependent on overall opening geometry. In physical terms this interdependence highlights the challenges in correctly predicting the airflow phenomena driving single sided ventilation for different types of ventilation components. An allowance for wind direction, opening height, characteristic aspect ratio and opening elevation is required as these will all affect ventilation rates. In conclusion the following points can be made:

- In single sided ventilation for low wind patterns $\left(v_{w}<4.0 \mathrm{~ms}^{-1}\right)$ wind direction plays an important role in determining whether buoyancy forces can properly establish.

- The opening geometry is important in determining whether this low wind pattern dependency emerges at all and the opening height, aspect ratio and opening elevation are key parameters in determining subsequent effects of wind.

- Slot louvre systems act as flow stabilizers dampening the unsteadiness characteristics of ventilation and enhance the assistive contribution to buoyancy from windward momentum forces potentially damping the mixing effects from turbulent diffusion in the opening.

If $\sigma_{\mathrm{c}}$ is taken as an indicator of internal airflow environment this suggests for single sided slot louvre ventilation the interdependence of opening geometry, wind speed and wind direction has a large influence on the effects of wind-generated air exchange mechanisms. Current semi empirical models for plain openings might not take proper account of this geometry dependent situation. Modification of thermophysical properties due to the retrofit have not necessarily reduced the magnitude of $A r^{0.5}$ for similar $F_{R}$ values although wind driving forces can have an increased contribution in low energy spaces even though the slot louvre system is generally perceived as restricting flow. Additional measurements in the retrofit space comparing a plain opening with that where a louvre is installed should give further insight into how wind shear interactions with buoyant flow are modified with the slotted geometry generating differing ventilation rates for similar opening areas. These measurements would include local velocity measurements at the opening and at the boundary allowing analysis of the spectra of turbulence for alternative geometries amongst other phenomena; such measurements are under currently in progress.

\section{ACKNOWLEDGEMENTS}

The authors wish to thank Dr Peter Warren for his very helpful discussions and advice regarding the use of the Warren plots. The original pilot project works was supported through a grant from the Department of Education and Skills, Ireland. The authors wish to acknowledge the co-work of the pilot project design and research team in the design and development phases of the pilot project 
O'Sullivan PD and Kolokotroni M (2016). Non dimensional analysis and characterisation of driving forces for a single sided slot louver ventilation system. International Journal of Ventilation, Vol 14, 4, (doi:10.1080/14733315.2016.11684091)

\section{References}

Ai, Z.T., Mak, C.M. (2014) "Analysis of fluctuating characteristics of wind-induced airflow through a single opening using LES modeling and the tracer gas technique," Building and Environment, 80, 249-258

Caciolo, M., Cui, S., Stabat, P., Marchio, D. (2013) "Development of a new correlation for single-sided natural ventilation adapted to leeward conditions," Energy \& Buildings, 60, 372-382,

Caciolo, M., Stabat, P., Marchio, D. (2011) "Full scale experimental study of single-sided ventilation : Analysis of stack and wind effects," Energy \& Buildings, 43(7), 1765-1773,

Chiu, Y.-H., Etheridge, D.W. (2007) "External flow effects on the discharge coefficients of two types of ventilation opening," Journal of Wind Engineering and Industrial Aerodynamics, 95(4), 225-252,

Cockroft, J. P., \& Robertson, P. (1976), Ventilation of an enclosure through a single opening, Building and Environment, 11(1), 29-35

Crommelin, R. D., \& Vrins, E. M. H. (1988), Ventilation through a single opening in a scale model, Air Infiltration Review, 9(3), 11-15

Dascalaki, E., Santamouris, M., Argiriou, A., Helmis, C., Asimakopoulos, D.N., Papadopoulos, K., Soilemes, A. (1996) "On the combination of air velocity and flow measurements in single sided natural ventilation configurations," Energy and Buildings, 24(2), 155-165

Dascalaki, E., Santamouris, M., Argiriou, A., Helmis, C., Asimakopoulos, D. N., Papadopoulos, K., \& Soilemes, A. (1995). Predicting single-sided natural ventilation rates in buildings, Solar Energy, 55(5), 327-341

de Gids, W., \& Phaff, H. (1982). Ventilation rates and energy consumption due to open windows: a brief overview of research in the Netherlands. Air infiltration review, 4(1), 4-5

Etheridge, D., 2011. Natural Ventilation of Buildings: Theory, Measurement and Design, Wiley-Blackwell.

Etheridge, D.W., Sandberg, M.. (1996) Building Ventilation: Theory and Measurement, Wiley.

Grabe, J. Von (2013) "Flow resistance for different types of windows in the case of buoyancy ventilation," Energy and Buildings, 65, 516-522,

Von Grabe, J., Svoboda, P., Bäumler, A. (2014) "Window ventilation efficiency in the case of buoyancy ventilation," Energy and Buildings, 72, 203-211

Heiselberg, P., Svidt, K., Nielsen, P. (2001) "Characteristics of airflow from open windows," Building and Environment, 36, 859-869

Hughes, B.R., Ghani, S. a a A. (2010) 'A numerical investigation into the effect of Windvent louvre external angle on passive stack ventilation performance', Building and Environment, 45(4), 1025-1036.

Irving, S., Etheridge, D., Ford, B. (2005) Natural Ventilation in Non-Domestic Buildings CIBSE AM10, The Chartered Institution of Building Services Engineers, CIBSE.

Kang, J.H., Lee, S.J. (2008) 'Improvement of natural ventilation in a large factory building using a louver ventilator', Building and Environment, 43(12), 2132-2141.

Karava, P., Stathopoulos, T., Athienitis, A. (2004) "Wind driven flow through openings-a review of discharge coefficients," International Journal of Ventilation, 3(3)

Larsen, T.S., Heiselberg, P. (2008) "Single-sided natural ventilation driven by wind pressure and temperature difference," Energy and Buildings, 40(6), 1031-1040

Mardia, K. V. (1972). Statistics of directional data, Academic Press

Nakanishi, T., Nakamura, T., Watanabe, Y., Handou, K., Kiwata, T. (2007) Technical Paper: Investigation of Air Flow Passing through Louvers.

O'Sullivan, P., Kolokotroni, M. (2014) "Time-averaged single sided ventilation rates and thermal environment in cooling mode for a low energy retrofit envelope system." International Journal of Ventilation, 13(2) 153-168

Pinnock, D. (2000) An Investigation into the Influence of Wind in Single-Sided Natural Ventilation, available: https://dspace.lboro.ac.uk/xmlui/handle/2134/7465

Sharples, S., Chilengwe, N. (2006) "Performance of ventilator components for natural ventilation applications," Building and Environment, 41(12), 1821-1830,

Van der Maas, J. (1992). Air Flow Through Large Openings in Buildings (Subtask 2): IEA Annex 20-Air Flow Patterns Within Buildings, LESO-PB, EPEL, CH-1015. International Energy Agency, Lausanne, Switzerland 
O'Sullivan PD and Kolokotroni M (2016). Non dimensional analysis and characterisation of driving forces for a single sided slot louver ventilation system. International Journal of Ventilation, ol 14, 느, (doi:10.1080/14733315.2016.11684091)

Wang, H., Chen, Q. (2012) “A new empirical model for predicting single-sided, wind-driven natural ventilation in buildings," Energy \& Buildings, 54, 386-394,

Warren, P., Parkins, L. (1985) “Single-sided ventilation through open windows," ASHRAE SP49, (1), 